\title{
Radical C-N Borylation of Aromatic Amines Enabled by a Pyrylium Reagent
}

\author{
Yuanhong Ma, ${ }^{\dagger}$ Yue Pang, ${ }^{\dagger}$ Jan Niski, Markus Leutzsch, and Josep Cornella*
}

\begin{abstract}
Herein, we report a radical borylation of aromatic amines through a homolytic $\mathrm{C}\left(\mathrm{sp}^{2}\right)-\mathrm{N}$ bond cleavage. This method capitalizes on a simple and mild activation via a pyrylium reagent ('cPyry-OTf) thus priming the amino group for reactivity. The combination of terpyridine and a diboron reagent triggers a radical reaction which cleaves the $\mathrm{C}\left(\mathrm{sp}^{2}\right)-\mathrm{N}$ bond and forges a new $\mathrm{C}\left(\mathrm{sp}^{2}\right)-$ $B$ bond. The unique non-planar structure of the pyridinium intermediate, provides the necessary driving force for the aryl radical for-mation. The method permits borylation of a wide variety of aromatic amines indistinctively of the electronic environment.
\end{abstract}

Primary aromatic amines represent a class of relevant functionalities present in a wide variety of contexts - from natural sources such as DNA or vitamins to synthetic molecules as part of their structure. ${ }^{[1]}$ Despite their potential as anchor points for further manipulation, direct functionalization of primary amino groups in (hetero)aromatic compounds has been a tremendous challenge in catalysis ${ }^{[2]}$ due to high energy of the $\mathrm{C}\left(\mathrm{sp}^{2}\right)-\mathrm{NH}_{2}$ bonds (BDE of $\left.\mathrm{C}_{6} \mathrm{H}_{5}-\mathrm{NH}_{2}: 102.6 \pm 1.0 \mathrm{kcal} / \mathrm{mol}\right),{ }^{[3]}$ coordination of the lone pair of the nitrogen to metal catalysts, and acid-base interactions with polar functionalities. To circumvent such drawbacks, approaches to cleave $\mathrm{C}-\mathrm{N}$ bonds have relied on the preactivation of the amino group, converting them into virtuous leaving groups, for example via diazotization, ${ }^{[4]}$ polyalkylation ${ }^{[5]}$ and others ${ }^{[6]}$ (Figure $1 \mathrm{~A}$ ). However, despite the wealth of reports in this area, several challenges remain. For example, diazotization reactions require the use of strong oxidants and acids, to generate the corresponding diazonium salts, which are thermally unstable and explosive (Figure 1A, path a). ${ }^{[4]}$ The use of an excess of toxic alkylating reagents restricts the functional group tolerance in complex settings for polyalkylation strategies (Figure 1A, path b). ${ }^{[5]}$ Although limited in functional group tolerance and scope, approaches based on transition metals have recently appeared, enabling the cleavage and functionalization of aniline derivatives (Figure 1, path c). ${ }^{[6]}$

Seminal work by Katritzky demonstrated the possibility of converting amino groups into good leaving groups by condensation with a pyrylium salt (Figure $1 \mathrm{~A}$, path $\mathrm{d}$ ). ${ }^{[7]}$ This strategy is characterized by the remarkable stability of the pyridinium salt intermediates, high selectivity for the amino groups and benefits from the high practicality and simplicity. Indeed, pyridinium salts have recently been employed to unlock SET processes based on transition metal or photoredox catalysts, and have been shown to be a powerful tool for constructing a myriad of chemical bonds. ${ }^{[8-11]}$ However, the wealth of literature in this area has been focused on the generation of alkyl radicals (Fig. 1B, top). Yet, methods which capitalize on pyridinium salts to

[a] Dr. Y. Ma, ${ }^{\dagger}$ Y. Pang, ${ }^{\dagger}$ J. Niski, Dr. M. Leutzsch, and Dr. J. Cornella Max-Planck-Institut für Kohlenforschung, Kaiser-Wilhelm-Platz 1, Mülheim an der Ruhr, 45470, Germany.

E-mail: cornella@kofo.mpg.de (J.C.)

†These authors contributed equally to this work.

Supporting information for this article is given via a link at the end of the document. generate aryl radicals through SET are virtually inexistent (Fig. $1 \mathrm{~B}$, bottom), ${ }^{[12]}$ mainly due to the disfavored thermodinamics for the aryl radical formation. Based on our recent interest on pyrylium reagents, ${ }^{[13]}$ we set out to explore this approach in the context of radical borylations using diboron reagents, as they have been shown to be excellent radical acceptors. ${ }^{[14-17]}$ Herein we report a protocol for the borylation of (hetero)aromatic amines via a SET process, enabled by the use of a tethered pyrylium salt (ScPyry-OTf). ${ }^{[18]}$ The structure of this pyrylium reagent proved unique in assisting the cleavage of the $\mathrm{C}\left(\mathrm{sp}^{2}\right)-\mathrm{N}$ bond, a feature beyond the capabilities of other common pyrylium activators. Moreover, the choice of the solvent was also crucial to achieve high yields of the corresponding organoboron compounds. The protocol has been demonstrated to be scalable and tolerant to a wide variety of functionalities.

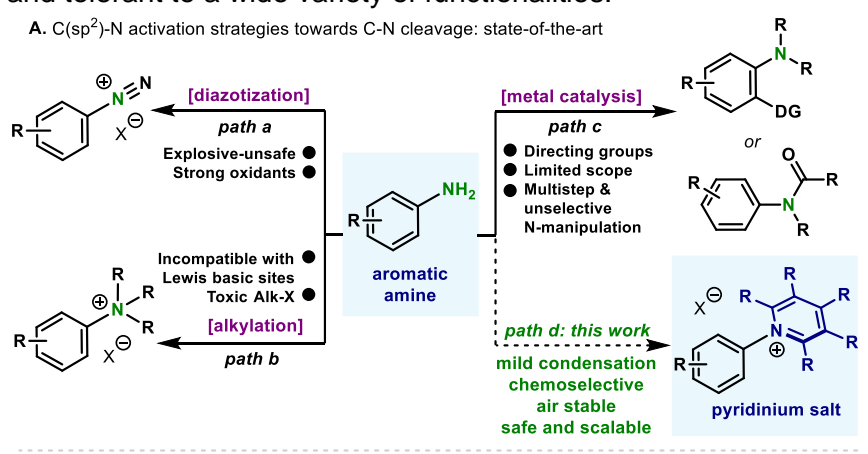

B. Radical approach to C-N cleavage via pyridinium salts

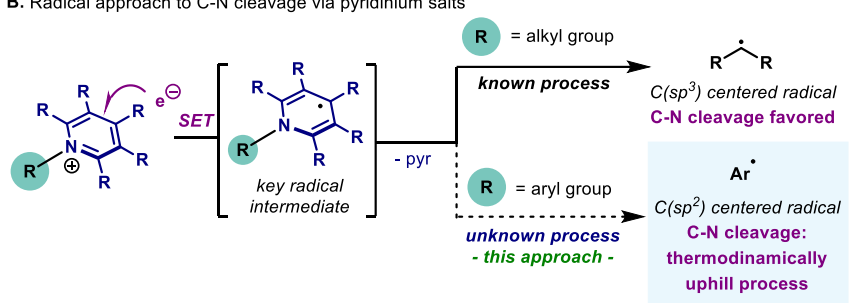

Figure 1. A) Strategies to prime the amino group for reactivity. B) Generation of aromatic radicals is a thermodynamically disfavored process.

Based on recent reports on the borylation of alkyl pyrydinium salts, ${ }^{[11]}$ we started our investigations on the borylation of anilines using $\mathrm{B}_{2} \mathrm{cat}_{2}$ (bis(catecholato)diboron). After screening of the reaction parameters, terpyridine (terpy) was identified as the Lewis-base of choice, performing the reaction at $130{ }^{\circ} \mathrm{C}$, using ${ }^{\prime} \mathrm{Pr}_{2} \mathrm{NC}(\mathrm{O}) \mathrm{Me}$ as solvent. ${ }^{[19]}$ Interestingly, under the optimized conditions, none of the classical pyridinium salts commonly employed proved efficient in the borylation reaction (Table 1A, 1-3). Then, we turned our attention to the tethered pyrylium reagent initally reported by Katritzky in the context of alkyl amine activation. ${ }^{[20]}$ It was the pyridinium 4-OTf that delivered excellent yields of $\mathrm{C}-\mathrm{B}$ bond formation 5 (Table 1A, entry $1,82 \%)$. When the counterion in 4 was replaced by $\mathrm{BF}_{4}$ $\left(4-B_{4}\right)$, a lower yield was obtained $(57 \%)$. The effect of the solvent was also remarkable: while DMF and DMAc failed to deliver good yields of product (entries 2 and 3 ), the use of a more sterically hindered amide such as ${ }^{i} \mathrm{Pr}_{2} \mathrm{NC}(\mathrm{O}) \mathrm{Me}$ proved to be crucial for obtaining high yields. While in the absence of Lewis-base the reaction afforded only $10 \%$ of 5 (entry 4 ), the 
use of bipyridine derivatives did not reach the levels of reactivity of terpy (entries 5 and 6). Although borylation strategies based on $\mathrm{B}_{2}$ pin $_{2}$ and aromatic Lewis bases have recently appeared in the literature, ${ }^{[15 f, 15 h, 16 b]}$ the use of this diboron reagent resulted in no conversion of 4-OTf (entry 7). Heating the reaction further had no effect on the reactivity (entry 8) and $120{ }^{\circ} \mathrm{C}$ proved insufficient to obtain high yields of $\mathbf{5}$ (entry 9 ). Isolation of $\mathbf{5}$ proceeded through the conversion of the sensitive $\mathrm{Ar}-\mathrm{B}$ (cat) into the corresponding Ar-Bpin reagent, by a simple quench with pinacol and $\mathrm{Et}_{3} \mathrm{~N}$. However, a quenching protocol based on MIDA resulted in slightly higher yields and afforded a more robust organoboron compound (6). ${ }^{[21,22]}$ Of note, the synthesis of the ScPyry-OTf (7) could be conducted similarly to the parent 2,4,6-triphenylpyrylium reagent. ${ }^{[20 a]}$ Commercially available tetralone $(\$ 0.26 / \mathrm{g}),{ }^{[23]}$ condenses with benzaldehyde, which upon addition of $\mathrm{TfOH}$, pure 7 precipitates as a bright yellow solid. The protocol could be scaled-up to $>30$ grams in one run, without any complicated setup (Table 1B).

Table 1. Optimization of the borylation of arylpyridinium salts. ${ }^{[a]}$ A. Optimization of the thermal borylation of arylpyridinium salts
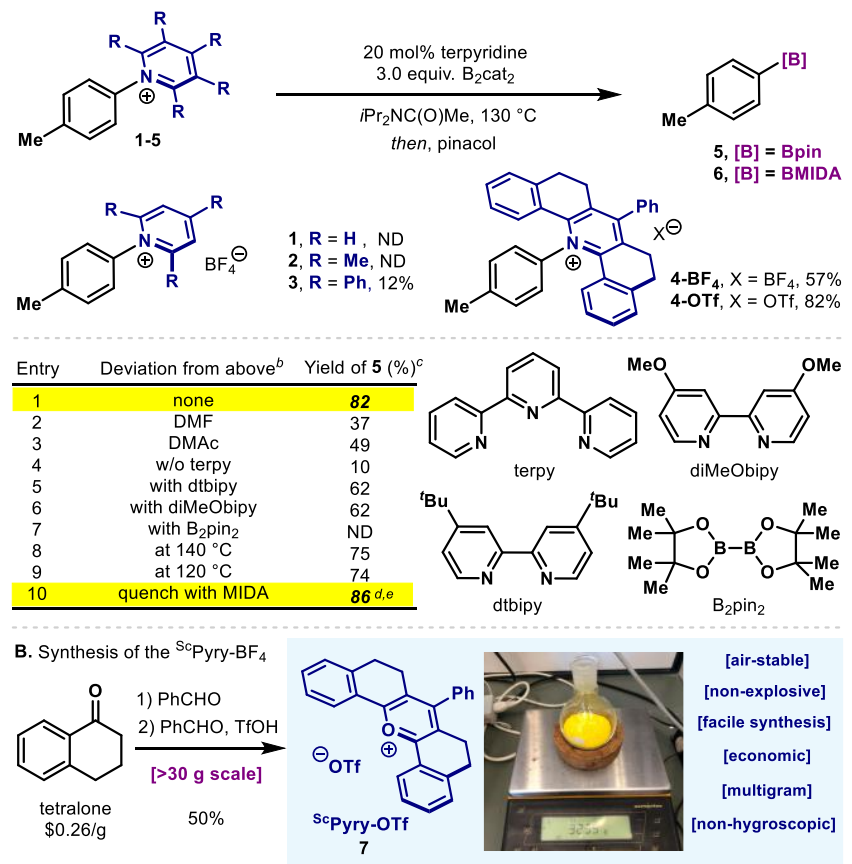

[air-stable] [non-explosive] [facile synthesis] [economic] [multigram] [non-hygroscopic]

[a] 1-4 $(0.1 \mathrm{mmol}), \mathrm{B}_{2} \mathrm{Cat}_{2}(0.3 \mathrm{mmol})$, terpy $(20 \mathrm{~mol} \%), \mathrm{iPr}_{2} \mathrm{NCOMe}(0.5 \mathrm{~mL})$ at $130{ }^{\circ} \mathrm{C}$ for $24 \mathrm{~h}$; then pinacol $(0.6 \mathrm{mmol})$ and $\mathrm{Et}_{3} \mathrm{~N}(0.5 \mathrm{~mL})$ were added and stirred for additional $2 \mathrm{~h}$ at $25^{\circ} \mathrm{C}$. ${ }^{[b]}$ Using 4-OTf as starting material. ${ }^{[c]}$ Yields determined by GC using dodecane as internal standard. ${ }^{[d]}$ Yield of isolated product $6 .{ }^{[\mathrm{e}]}$ Reaction performed at $0.25 \mathrm{mmol}$ for $12 \mathrm{~h}$, then MIDA (1.5 mmol) for $4 \mathrm{~h}$ at $90^{\circ} \mathrm{C}$. MIDA $=N$-methyliminodiacetic acid. ND $=$ not detected.

With the optimal protocol in hand, we explored the scope of this new borylation strategy. It is worth noting that condensation of aromatic amines with 7 proceeded smoothly across the whole range of substrates (8-32) with an average yield of $>85 \% .{ }^{[19]}$ As shown in Table $2 \mathrm{~A}$, the borylation protocol boded well with anilines substituted at the meta- $(\mathbf{3 3})$ and para-positions $(\mathbf{3 4}, \mathbf{3 5})$. The presence of electron-deficient fluorinated moieties such as $\mathrm{CF}_{3}(36), \mathrm{OCF}_{3}(37)$ or $\mathrm{F}(\mathbf{3 8}, 39)$ did not affect the reactivity and provided good yields of boronic ester. The reaction could also be performed in a one-pot fashion as exemplified by 39; albeit in moderate yield.
Table 2. Scope of the radical borylation of (hetero)aromatic amines with a pyrylium salt. [a]

A. Scope of the borylation

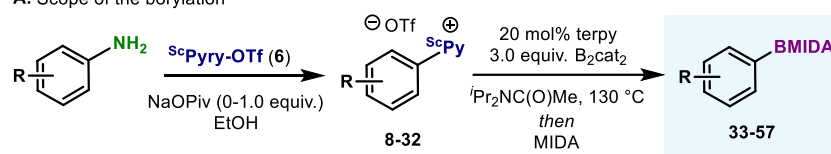

[EWG \& EDG groups] [heterocycles] [stable intermediates] [25 examples]
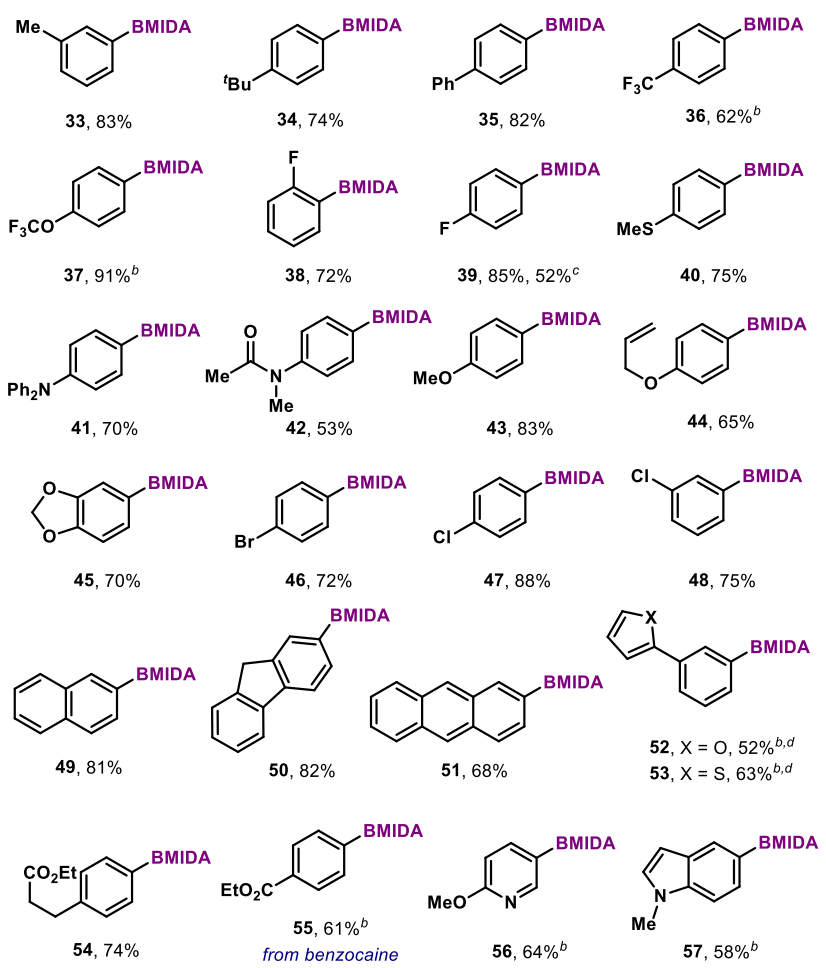

B. Gram-scale reaction

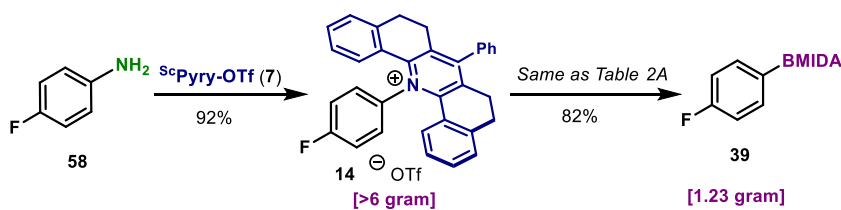

[a] Reaction conditions: Step 1: aromatic amine (1.05-1.50 equiv.), 7 (1.0 equiv.), NaOPiv (0-1.0 equiv.) in $\mathrm{EtOH}(0.2 \mathrm{M})$ at $85^{\circ} \mathrm{C}$; Step 2: pyridinium salt $(0.25 \mathrm{mmol}), \mathrm{B}_{2}$ cat2 $(0.75 \mathrm{mmol})$, terpyridine $(20 \mathrm{~mol} \%)$ in ${ }^{1} \mathrm{Pr}_{2} \mathrm{NC}(\mathrm{O}) \mathrm{Me}(0.2$ M) at $130{ }^{\circ} \mathrm{C}$ for $12 \mathrm{~h}$; then MIDA $(1.5 \mathrm{mmol})$ at $90{ }^{\circ} \mathrm{C}$ for $4 \mathrm{~h}$. Isolated yields for the borylation step. ${ }^{[b]} \mathrm{B}_{2} \mathrm{cat}_{2}(1.0 \mathrm{mmol})$ was used and $24 \mathrm{~h}$ reaction time. ${ }^{[\mathrm{c}]}$ Yield from aniline, without isolating the pyridinium intermediate (in situ). [d] ${ }^{i} \mathrm{Pr}_{2} \mathrm{NC}(\mathrm{O}) \mathrm{Me}(0.125 \mathrm{M})$.

Electron-releasing substituents in the aniline were also amenable, as exemplified by the presence of thioethers (40), tertiary amines (41), amides (42) and ethers (43-45). Notably, no Claisen rearrangement byproducts were observed for product 44 . Bromo- $(\mathbf{4 6})$ and chloroanilines $(\mathbf{4 7}, 48)$ were also compatible under the reaction conditions, thus providing boronic acid derivatives bearing orthogonal handles for further derivatization. Boronic acid derivatives of $\pi$-extended anilines such as naphthyl (49), fluorenyl (50) or anthracenyl (51) could also be synthesized in high yields. The presence of oxygen- (52) or sulfur-containing heterocycles (53) did not affect the formation of the $\mathrm{C}-\mathrm{B}$ bond. Anilines bearing aliphatic esters (54) or a benzoate motif, such as the anesthetic drug benzocaine, could also be borylated (55) in good yields. Finally, heterocyclic Ncontaining compounds such as pyridine (56) and indole (57) were amenable for borylation under the optimal conditions. As depicted in Table 2B, both the condensation and the borylation 
proved to be highly scalable, as demonstrated by the $>6$ grams of pyrylium 14 provided and the 1.23 grams of borylated compound 39.

At this point, we set out to explore the remarkable effects for both the solvent of choice and the structure of the pyrylium. As shown in Table 1, when $\mathbf{3}$ was subjected to the optimized conditions using DMAc, no borylation was obtained and $>90 \%$ of starting pyridinium salt was recovered (Figure 2A). When ${ }^{2} \mathrm{Pr}_{2} \mathrm{NC}(\mathrm{O}) \mathrm{Me}$ was used instead, a minimal yield of $\mathbf{5}$ was obtained (12\%). However, the conversion was low and the reaction was plagued with several unidentified byproducts. In stark contrast, when 4-OTf was subjected to the borylation conditions in DMAc, acceptable yields of borylation were obtained (49\%, Table 1, entries 3). Analysis of the reaction mixture revealed the formation of a major by-product, which was identified as the reduced compound 59.[24] This compound slowly decomposed when exposed to air and light after long periods of time to afford 60 and 61 . Gratifyingly, when the solvent was replaced by the optimal ${ }^{2} \mathrm{Pr}_{2} \mathrm{NC}(\mathrm{O}) \mathrm{Me}$, formation of by-product 59 was suppressed $(<5 \%)$, and excellent yields of 5 were obtained ( $82 \%$, Table 1, entry 1). Performing the borylation reaction in the presence of 1,1-diphenylethene resulted in the formation of $5(53 \%)$ and the radical addition product $62(22 \%)$ (Figure 2B). This result offers evidence for the homolytic cleavage of the $\mathrm{C}-\mathrm{N}$ bond and the generation of aryl radicals in solution.

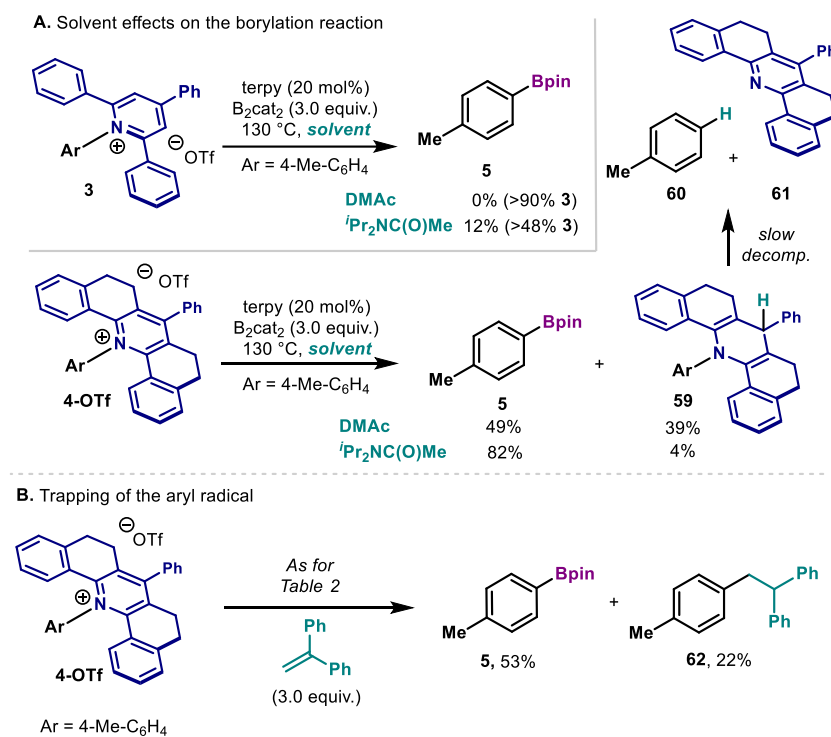

Figure 2. A) Reactivity of pyridinium salts 3 and 4-OTf with different solvents; B) Radical trap experiments confirming the presence of aryl radicals.

Motivated by the striking differences in reactivity between 3 and 4-OTf, we initially interrogated their electronic properties. Cyclic voltammetry experiments conducted in both compounds revealed a reversible behavior and a similar first reduction potential $\left(\mathrm{E}_{\text {red }}(\mathbf{3})=-1.39 \mathrm{~V}\right.$ vs $\mathrm{Fc} / \mathrm{Fc}^{+}$in DMF, $\mathrm{E}_{\text {red }}(4-\mathrm{OTf})=-$ $1.30 \mathrm{~V}$ vs $\mathrm{Fc} / \mathrm{Fc}^{+}$in DMF). ${ }^{[19]}$ This result suggests that the oxidation capabilities of both pyridinium salts are similar, and reduction via SET processes should be equally facile using the terpy/ $\mathrm{B}_{2} \mathrm{cat}_{2}$ system. ${ }^{[11 \mathrm{~b}, 25]}$ However, $\mathrm{X}$-ray analysis of the crystal structure for $\mathbf{3}$ and $\mathbf{4}-\mathbf{B F}_{4}$ was far more revealing. Similarly to $61,{ }^{[26]}$ the pyridine moiety in $\mathbf{3}$ is planar, with almost no torsion observed in the pyridinium ring (Figure $3 \mathrm{~A}$, left). On the other hand, the ethane-bridged moiety in $\mathbf{4}-\mathbf{B F}_{\mathbf{4}}$, renders a much more constraint environment and results in a heavily tensioned aromatic pyridinium motif, as judged by the remarkable $11.2^{\circ},-$ $174.4^{\circ}$ and $5.8^{\circ}$ of torsion for the three different angles explored (Figure $3 \mathrm{~A}$, right). Based on these experimental data, a putative mechanism for this transformation is depicted in Figure 3B. As suggested in previous Lewis-base-promoted borylation strategies, ${ }^{[11 a]}$ we propose an initial reduction of the pyridinium moiety by the reducing power of the combined terpy and $\mathrm{B}_{2} \mathrm{Cat}_{2}$ mixture, to generate int-1 (Figure 3B). The high degree of distortion of the aromatic ring in 4-OTf led us to postulate that int- 1 would be highly unstable, and homolytic $\mathrm{C}-\mathrm{N}$ cleavage occurs. We speculate that the restoration of the planarity renders a higher degree of conjugation and aromaticity for 61 and provides the necessary driving force for the homolysis of the $\mathrm{C}-\mathrm{N}$ bond. As aforementioned, when DMAc was used competing formation of 59 occurs. However, the use of ${ }^{2} \mathrm{Pr}_{2} \mathrm{NC}(\mathrm{O}) \mathrm{Me}$ inactivates possible such side pathways (HAT or over reduction), and aryl radical formation through $\mathrm{C}-\mathrm{N}$ scission is largely operative. Although the nature of this difference in reactivity is still under investigation, we propose that the success of this solvent hinges on providing an adequate balance for a successful radical chain towards productive borylation. The aryl radical formed, is then rapidly trapped by a boron-containing intermediate, delivering the desired $\mathrm{C}-\mathrm{B}$ bond. ${ }^{[16 \mathrm{~g}]}$
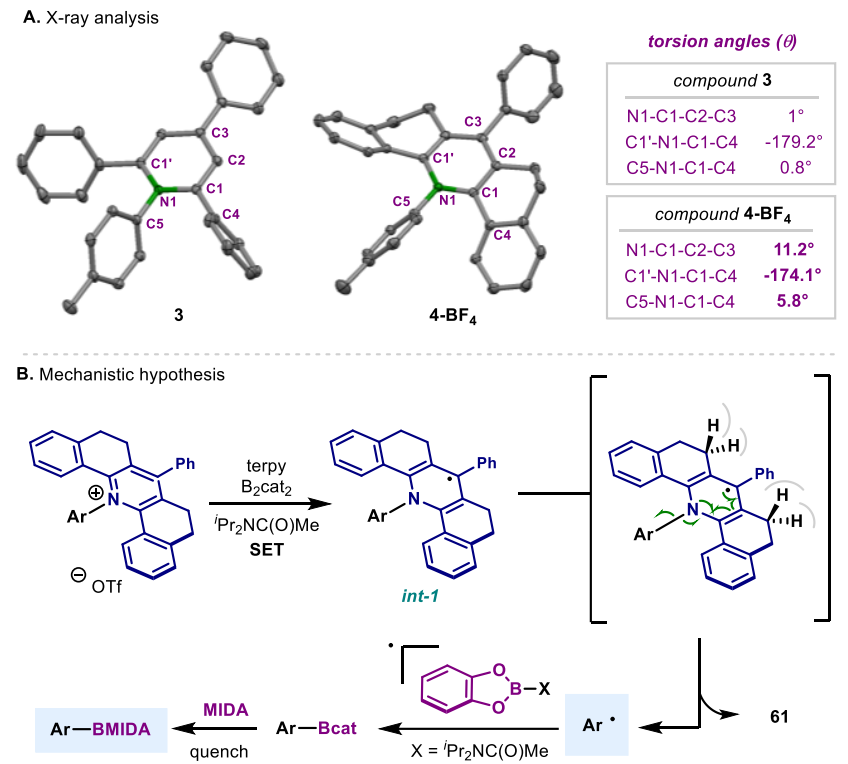

Figure 3. A) X-ray structures of 3 and $4-B_{4}$. Counterions are omitted for clarity; B) Putative mechanism for the catalytic borylation reaction of pyridinium salts.

In summary, we have developed a novel strategy for the $\mathrm{C}-\mathrm{N}$ borylation of aromatic amines, capitalizing on the mild and selective condensation of ScPyry-OTf (7) with amino groups. Additionally, the rationally designed solvent permits the taming of highly reactive aryl radicals to engage in a $\mathrm{C}-\mathrm{B}$ bond forming event. The borylation protocol is demonstrated to be scalable and is tolerant to various functional groups. The ability of pyridinium salts derived from scPyry-OTf (7) to successfully generate aryl radicals, represents a new approach in the area of C-N functionalization. Research exploiting ScPyry-OTf (7) for other applications in organic synthesis is currently ongoing in our research laboratories. 


\section{Acknowledgements}

Financial support for this work was provided by Max-PlanckGesellschaft, Max-Planck-Institut für Kohlenforschung and Fonds der Chemischen Industrie (FCl-VCl). Y. P. thanks the CSC for a PhD scholarship. We thank Dr. Y. Duan and J. Busch for their contributions. We thank Dr. C. Werlé and P. Höfer for help in cyclic voltammetry studies. We are thankful to Prof. Dr. A. Fürstner for discussions and generous support.

Keywords: aromatic amine $\cdot$ radical borylation $\cdot \mathrm{C}-\mathrm{N}$ bond functionalization $\cdot$ pyrylium $•$ pyridinium salts

[1] a) S. A. Lawrence, Amines: Synthesis, Properties and Applications Cambridge University Press: Cambridge, 2004; b) A. Ricci, Amino Group Chemistry: From Synthesis to the Life Science. Wiley-VCH: Weinheim, 2008.

[2] For reviews of transition-metal catalyzed $\mathrm{C}-\mathrm{N}$ bond activation, see: a) $\mathrm{K}$ Ouyang, W. Hao, W.-X. Zhang, Z. Xi, Chem. Rev. 2015, 115, 12045 12090; b) Q. Wang, Y. Su, L. Li, H. Huang, Chem. Soc. Rev. 2016, 45, 1257-1272.

[3] Y. R. Luo, Comprehensive Handbook of Chemical Bond Energies. CRC Press: Boca Raton, 2007

[4] For reviews of $\mathrm{C}-\mathrm{N}$ activation via arene diazonium salts, see: a) A. Roglans, A. Pla-Quintana, M. Moreno-Mañas, Chem. Rev. 2006, 106 4622-4643; b) F. Mo, G. Dong, Y. Zhang, J. Wang, Org. Biomol. Chem. 2013, 11, 1582-1593; c) L. He, G. Qu, Y. Gao, J. Wu, Org. Biomol. Chem. 2014, 12, 6965-6971; d) F. Mo, D. Qiu, Y. Zhang, J. Wang, Acc. Chem. Res. 2018, 51, 496-506.

[5] For selected examples of $\mathrm{C}-\mathrm{N}$ activation via aryl trialkylammonium salts, see: a) E. Wenkert, A.-L. Han, C.-J. Jenny, J. Chem. Soc., Chem. Commun. 1988, 975-976; b) S. B. Blakey, D. W. C. MacMillan, J. Am Chem. Soc. 2003, 125, 6046-6047; c) J. T. Reeves, D. R. Fandrick, Z. Tan, J. J. Song, H. Lee, N. K. Yee, C. H. Senanayake, Org. Lett. 2010, 12, 4388-4391; d) L.-G. Xie, Z.-X. Wang, Angew. Chem. Int. Ed. 2011 50, 4901-4904; Angew. Chem. 2011,123, 5003-5006; e) F. Zhu, J.-L. Tao, Z.-X. Wang, Org. Lett. 2015, 17, 4926-4929; f) T. Uemura, M. Yamaguchi, N. Chatani, Angew. Chem. Int. Ed. 2016, 55, 3162-3165; Angew. Chem. 2016,128, 3214-3217; g) D.-Y. Wang, M. Kawahata, Z. K. Yang, K. Miyamoto, S. Komagawa, K. Yamaguchi, C. Wang, M. Uchiyama, Nat. Commun. 2016, 7, 12937; h) D.-Y. Wang, Z.-K. Yang, C. Wang, A. Zhang, M. Uchiyama, Angew. Chem. Int. Ed. 2018, 57 3641-3645; Angew. Chem. 2018,130, 3703-3707; i) R.-D. He, C.-L. Li, Q.-Q. Pan, P. Guo, X.-Y. Liu, X.-Z. Shu, J. Am. Chem. Soc. 2019, 141 12481-12486; j) A. W. Rand, J. Montgomery, Chem. Sci. 2019, 10 5338-5344.

[6] For selected examples of transition-metal catalyzed $\mathrm{C}-\mathrm{N}$ activation, see: a) S. Ueno, N. Chatani, F. Kakiuchi, J. Am. Chem. Soc. 2007, 129, 6098-6099; b) T. Koreeda, T. Kochi, F. Kakiuchi, J. Am. Chem. Soc 2009, 131, 7238-7239; c) M. Tobisu, K. Nakamura, N. Chatani, J. Am. Chem. Soc. 2014, 136, 5587-5590; d) S.-E. Wang, L. Wang, Q. He, R. Fan, Angew. Chem. Int. Ed. 2015, 54, 13655-13658; Angew. Chem. 2015,127, 13859-13862; e) X. Cong, F. Fan, P. Ma, M. Luo, H. Chen, X Zeng, J. Am. Chem. Soc. 2017, 139, 15182-15190; f) Z.-C. Cao, X.-L. Li, Q.-Y. Luo, H. Fang, Z.-J. Shi, Org. Lett. 2018, 20, 1995-1998; g) Z.C. Cao, S.-J. Xie, H. Fang, Z.-J. Shi, J. Am. Chem. Soc. 2018, 140, 13575-13579; h) D. Han, Q. He, R. Fan, Nat. Commun. 2018, 9, 3423; i) Z. Zhang, D. Zheng, Y. Wan, G. Zhang, J. Bi, Q. Liu, T. Liu, L. Shi, J. Org. Chem. 2018, 83, 1369-1376; j) Z.-B. Zhang, C.-L. Ji, C. Yang, J. Chen, X. Hong, J.-B. Xia, Org. Lett. 2019, 21, 1226-1231.

[7] For reviews of seminal work of Katritzky: a) A. R. Katritzky, C. M. Marson, Angew. Chem. Int. Ed. 1984, 23, 420-429; Angew. Chem. 1984, 96, 403-413; b) A. T. Balaban, 2,4,6-Triphenylpyrylium Tetrafluoroborate. In Encyclopedia of Reagents for Organic Synthesis, 2001.

[8] For recent reviews of $C-N$ activation via pyridinium salts: a) D. Kong, $P$. J. Moon, R. J. Lundgren, Nat. Catal. 2019, 2, 473-476; b) F.-S. He, S.
Ye, J. Wu, ACS Catal. 2019, 9, 8943-8960. c) Y. Pang, D. Moser, J. Cornella, Synthesis 2019, DOI: 10.1055/s-0039-1690703; d) S. L. Rössler, B. J. Jelier, E. Magnier, G. Dagousset, E. M. Carreira, A. Togni, Angew. Chem. Int. Ed. 2019, DOI: 10.1002/anie.201911660; Angew. Chem. 2019, DOI:10.1002/ange.201911660.

[9] For recent transition-metal catalyzed transformations using alkylpyridinium salts, see: a) C. H. Basch, J. Liao, J. Xu, J. J. Piane, M. P. Watson, J. Am. Chem. Soc. 2017, 139, 5313-5316; b) W. Guan, J. Liao, M. P. Watson, Synthesis 2018, 50, 3231-3237; c) Liao, J.; Guan, W.; Boscoe, B. P.; Tucker, J. W.; Tomlin, J. W.; Garnsey, M. R.; Watson, M. P. Org. Lett. 2018, 20, 3030-3033; d) M. E. Hoerrner, K. M. Baker, C. H. Basch, E. M. Bampo, M. P. Watson, Org. Lett. 2019, 21, 7356-7360; e) C.-L. Li, X. Jiang, L.-Q. Lu, W.-J. Xiao, X.-F. Wu, Org. Lett. 2019, 21, 6919-6923; f) J. Liao, C. H. Basch, M. E. Hoerrner, M. R. Talley, B. P. Boscoe, J. W. Tucker, M. R. Garnsey, M. P. Watson, Org. Lett. 2019, 21, 2941-2946; g) R. Martin-Montero, V. R. Yatham, H. Yin, J. Davies, R. Martin, Org. Lett. 2019, 21, 2947-2951; h) S. Ni, C.-X. Li, Y. Mao, J. Han, Y. Wang, H. Yan, Y. Pan, Sci. Adv. 2019, 5, eaaw9516; i) S. Plunkett, C. H. Basch, S. O. Santana, M. P. Watson, J. Am. Chem. Soc. 2019, 141, 2257-2262; j) S.-Z. Sun, C. Romano, R. Martin, J. Am. Chem. Soc. 2019, 141, 16197-16201; k) H. Yue, C. Zhu, L. Shen, Q. Geng, K. J. Hock, T. Yuan, L. Cavallo, M. Rueping, Chem. Sci. 2019, 10, 4430-4435.

[10] For photoredox catalysis or photo-induced reactions using alkylpyridinium salts, see: a) F. J. R. Klauck, M. J. James, F. Glorius, Angew. Chem. Int. Ed. 2017, 56, 12336-12339; Angew. Chem. 2017,129 12505-12509; b) M. Ociepa, J. Turkowska, D. Gryko, ACS Catal. 2018 8, 11362-11367; c) M.-M. Zhang, F. Liu, Org. Chem. Front. 2018, 5, 3443-3446; d) M.-C. Fu, R. Shang, B. Zhao, B. Wang, Y. Fu, Science 2019, 363, 1429; e) M. J. James, F. Strieth-Kalthoff, F. Sandfort, F. J. R. Klauck, F. Wagener, F. Glorius, Chem. Eur. J. 2019, 25, 8240-8244; f) X. Jiang, M.-M. Zhang, W. Xiong, L.-Q. Lu, W.-J. Xiao, Angew. Chem. Int. Ed. 2019, 58, 2402-2406; Angew. Chem. 2019,131, 2424-2428; g F. J. R. Klauck, H. Yoon, M. J. James, M. Lautens, F. Glorius, ACS Catal. 2019, 9, 236-241; h) J. Wu, P. S. Grant, X. Li, A. Noble, V. K. Aggarwal, Angew. Chem. Int. Ed. 2019, 58, 5697-5701; Angew. Chem. 2019,131, 5753-5757; i) Z.-K. Yang, N.-X. Xu, C. Wang, M. Uchiyama Chem. Eur. J. 2019, 25, 5433-5439; j) Z.-F. Zhu, M.-M. Zhang, F. Liu, Org. Biomol. Chem. 2019, 17, 1531-1534; k) J. Yi, S. O. Badir, L. M Kammer, M. Ribagorda, G. A. Molander, Org. Lett. 2019, 21, 33463351.

[11] For photo-induced and thermal borylation using alkylpyridinium salts, see: a) J. Hu, G. Wang, S. Li, Z. Shi, Angew. Chem. Int. Ed. 2018, 57, 15227-15231; Angew. Chem. 2018,130, 15447-15451; b) F. Sandfort, F. Strieth-Kalthoff, F. J. R. Klauck, M. J. James, F. Glorius, Chem. Eur. J. 2018, 24, 17210-17214; c) J. Wu, L. He, A. Noble, V. K. Aggarwal, J. Am. Chem. Soc. 2018, 140, 10700-10704.

[12] The early examples using arylpyridinium salts possibly via SET process were reported by Katritzky, however, these reactions either gave very low yields or were run under very harsh conditions. See: a) A. R Katritzky, N. F. Eweiss, P.-L. Nie, J. Chem. Soc., Perkin Trans. 1 1979, 433-435; b) A. R. Katritzky, S. S. Thind, J. Chem. Soc., Perkin Trans. 1 1980, 865-868; c) A. R. Katritzky, D. K. Wittmann, J.-L. Chen, C. M. Marson, J. Ossana, Heterocycl. Chem. 1986, 23, 865-870.

[13] a) D. Moser, Y. Duan, F. Wang, Y. Ma, M. J. O'Neill, J. Cornella, Angew. Chem. Int. Ed. 2018, 57, 11035-11039; Angew. Chem. 2018,130 11201-11205; b) Gómez-Palomino, A.; Cornella, J. Angew. Chem. Int. Ed. 2019, DOI: 10.1002/anie.201910895; Angew. Chem. 2019 DOI:10.1002/ange.201910895.

[14] For reviews of radical borylations, see: a) G. Yan, D. Huang, X. Wu Adv. Synth. Catal. 2018, 360, 1040-1053; b) F. W. Friese, A. Studer, Chem. Sci. 2019, 10, 8503-8518.

[15] For selected examples of radical borylation using diazonium salts as aryl radical precursors, see: a) F. Mo, Y. Jiang, D. Qiu, Y. Zhang, J. Wang, Angew. Chem. Int. Ed. 2010, 49, 1846-1849; Angew. Chem. 2010,122, 1890-1893; b) D. Qiu, L. Jin, Z. Zheng, H. Meng, F. Mo, X. Wang, Y. Zhang, J. Wang, J. Org. Chem. 2013, 78, 1923-1933; c) J. Yu, L. Zhang, G. Yan, Adv. Synth. Catal. 2012, 354, 2625-2628; d) W. Erb, 
M. Albini, J. Rouden, J. Blanchet, J. Org. Chem. 2014, 79, 1056810580.

[16] For selected examples of radical borylation using aryl halides as aryl radical precursors, see: a) J. Zhang, H.-H. Wu, J. Zhang, Eur. J. Org Chem. 2013, 6263-6266; b) K. Chen, S. Zhang, P. He, P. Li, Chem. Sci 2016, 7, 3676-3680; c) M. Jiang, H. Yang, H. Fu, Org. Lett. 2016, 18 5248-5251; d) A. M. Mfuh, J. D. Doyle, B. Chhetri, H. D. Arman, O. V. Larionov, J. Am. Chem. Soc. 2016, 138, 2985-2988; e) A. M. Mfuh, V. T. Nguyen, B. Chhetri, J. E. Burch, J. D. Doyle, V. N. Nesterov, H. D. Arman, O. V. Larionov, J. Am. Chem. Soc. 2016, 138, 8408-8411; f) L. Zhang, L. Jiao, J. Am. Chem. Soc. 2017, 139, 607-610; g) Y. Cheng, C Mück-Lichtenfeld, A. Studer, Angew. Chem. Int. Ed. 2018, 57, 16832 16836; Angew. Chem. 2018,130, 17074-17078; h) L. Zhang, L. Jiao, J. Am. Chem. Soc. 2019, 141, 9124-9128.

[17] For selected examples of radical borylation using other aryl radical precursors, see: a) C. Zhu, M. Yamane, Org. Lett. 2012, 14, 45604563; b) L. Candish, M. Teders, F. Glorius, J. Am. Chem. Soc. 2017, 139, 7440-7443; c) W.-M. Cheng, R. Shang, B. Zhao, W.-L. Xing, Y. Fu, Org. Lett. 2017, 19, 4291-4294; d) W. Liu, X. Yang, Y. Gao, C.-J. Li, J. Am. Chem. Soc. 2017, 139, 8621-8627; e) M. Teders, A. GómezSuárez, L. Pitzer, M. N. Hopkinson, F. Glorius, Angew. Chem. Int. Ed. 2017, 56, 902-906; Angew. Chem. 2017,129, 921-925.

[18] The "Sc" superindex in ScPyry-OTf was chosen to differentiate this reagent from other similar pyrylium reagents such as Pyry-BF 4 .

[19] See supporting information for details.

[20] a) A. R. Katritzky, S. S. Thind, J. Chem. Soc., Perkin Trans. 1 1980, 1895-1900; b) A. R. Katritzky, A. M. El-Mowafy, G. Musumarra, K. Sakizadeh, C. Sana-Ullah, S. M. M. El-Shafie, S. S. Thind, J. Org. Chem. 1981, 46, 3823-3830; c) A. R. Katritzky, D. Lamba, R. Spagna A. Vacigo, R. Prewo, J. H. Bieri, J. J. Stezowski, G. Musumarra, J. Chem. Soc., Perkin Trans. 21987, 1391-1398.

[21] For reviews of $N$-Methyliminodiacetic Acid Boronates in organic synthesis, see: a) Z. He, A. Zajdlik, A. K. Yudin, Acc. Chem. Res. 2014 47, 1029-1040; b) J. Li, A. S. Grillo, M. D. Burke, Acc. Chem. Res. 2015, 48, 2297-2307.

[22] a) J. J. Hirner, D. J. Faizi, S. A. Blum, J. Am. Chem. Soc. 2014, 136, 4740-4745; b) D. Mazzarella, G. Magagnano, B. Schweitzer-Chaput, P. Melchiorre, ACS Catal. 2019, 9, 5876-5880.

[23] Price retrived from $\mathrm{TCl}$ at www.tcichemicals.com.

[24] Alternative procedure based on the reduction of 4-OTf with $\mathrm{Zn}$ and 1,4cyclohexadiene (CHD) also afforded compound 59, thus confirming its structure. See Supporting Information for details.

[25] L. Zhang, L. Jiao, Chem. Sci. 2018, 9, 2711-2722.

[26] G. Rusek, J. Mazurek, T. Lis, Chem. Pap. 2001, 55, 37-41. 
